DOI: 10.14451/1.166.39

\title{
ОЦЕНКА ЭКОНОМИЧЕСКОЙ ЭФФЕКТИВНОСТИ ДЕЯТЕЛЬНОСТИ ПРЕДПРИЯТИЯ В УПРАВЛЕНИИ ЕГО СТОИМОСТЬЮ
}

\author{
(c) 2018 Вейг Наталья Васильевна \\ кандидат экономических наук \\ докторант кафедры экономики и управления предприятиями и производственными комплексами \\ Санкт-Петербургский государственный экономический университет \\ 191023, Санкт-Петербург, ул. Садовая, д. 21 \\ E-mail:veyg_natalia@mail.ru
}

В статье систематизируются существующие понятия эффективности, устанавливается концептосфера понятия «эффективность». Показан генезис взглядов на понятие эффективности ряда ученых и раскрыт их вклад в развитие данной экономической категории с позиции диалектического анализа, стоимостного подхода к управлению.

Ключевые слова: эффект, эффективность, производительность, предприятие, стоимость предприятия, экономическая система.

Первый научный конгресс по кибернетике назвал теорию эффективности не наукой, а «искусством эффективного действия». А.Н. Колмогоров предвидел целое научное направление, изучающее системы «любой природы, способные воспринимать, хранить и перерабатывать информацию и использовать ее для управления и регулирования» [7], подчеркивая взаимосвязь кибернетики, математики, естественных и социальных наук. Понятие эффективности как раз и обобщает взаимодействие всех ныне известных наук - от механических, химических, биологических, информационных, социальных, управленческих, финансовых, экономических процессов до совсем новых - инновационных, обладающих приростом новых знаний. Кибернетика объединила три основные модели - надежность, информированность и действенность в понятии эффективности [16,17]. Изначально областью приложения понятия эффективности изначально была техника, далее наука об управлении (известная под названием теория эффективности организаций) и экономика.

\section{Эффективность в теории систем}

Теория эффективности рассматривается в целом ряде работ, при этом одни ученые утверждают, что теория эффективности еще далека от признания в качестве самостоятельной науки [15], другие же, имея противоположную точку зрения, указывают, что «объектом изучения теории эффективности являются целенаправленные действия - операции, а предметом - закономерности, связывающие эффективность операции с качеством системы, условиями и способами ее использования в операции» [10]. Предполагается, что теория эффективности имеет еще одно свое предназначение как «инструмент исследования операций» [12]. В науке и практике на Западе достаточно активно развивается схожее направление науки - анализ эффективности и продуктивности (производительности) (Efficiency and Productivity Analysis) $[21,22]$.

Методы теории эффективности призваны планировать, координировать, оценивать, обеспечивать обратную связь для адаптации и контроля результативности работы системы управления (любым социально-экономическим объектом, процессом, предприятием). Целеполаганием такой оценки результативности выступает обеспеченность рационального (оптимального) выбора/распределения имеющихся (ограниченных) ресурсов. Здесь важно подчеркнуть заложенный в методы управления эффективностью механизм адаптации к внешним условиям функционирования данной системы управления и наличие стратегических задач управления системой в целом.

Ее сущность заключается в оценке эффективности достижения системой цели и затраченными на это усилиями. Для большинства объектов исследования оценка эффективности носит характер прогнозирования и обладает вероятностными параметрами, определенными условиями функционирования (реализации) управленче- 
ских решений, основывается на общепринятых методах и моделях измерения эффективности и правильно подобранными критериями оценивания для данного объекта допустимым множеством (набором) решений.

В практике считается, что лучше предпочесть неоптимальное решение правильно выбранному критерию, нежели наоборот - оптимальное решение при неправильно выбранном критерии [23].

Множественность категории «эффективность», сложность ее терминологической идентификации и измерения - главные вопросы управления эффективностью в целом. В литературе практически всегда термин «эффективность» связывается и с системой, и с операциями, и с решением и целью деятельности.

Итак, эффективность (в переводе с латыни effectus означает совершение, исполнение, осуществление, результат) - способность выполнять какую-либо работу, осуществляя достижение желаемого результата с минимально возможными затратами времени и усилий. Понятие эффективности производства раскрывается как соотношение произведенного продукта к затратам на его производство. При этом возможна множественность трактовки при едином понимании сущности, что происходит из-за не всегда корректного перевода.

«Эффективность - наиболее общее, определяющее свойство любой целенаправленной деятельности, которое с познавательной (гносе- ологической) точки зрения раскрывается через категорию цели и объективно выражается степенью достижения цели с учетом затрат ресурсов и времени» [10]. Измерение эффективности системы невозможно осуществить, исходя только из свойств данной системы, так как согласно определению самой системы у нее должна быть управляющая подсистема со своими целями и задачами. Также необходимо учитывать возникающие эмерджентные и мультипликативные эффекты, которые могут носить двоякий характер. В системе могут возникать косвенные и побочные эффекты, а само измерение зачастую проводится косвенными или сравнительными методами. Вместе с тем из теории систем известно, не существуют двух одинаковых систем и закон многообразия Эшби также доказывает это определение [10).

На русский язык термин «эффективность» переводится с английских выражений «effectiveness», «efficiency», «efficientia», а время от времени используется и понятие «performance» (рис. 1).

Первое из них подразумевает способность установки желаемых целей и достижения их. Смысл второго термина - в соотнесении и измерении полученных выгод (результатов) с теми ресурсами, которые были затрачены для получения указанных результатов [22]. Термин «performance» можно перевести как степень эффективности функционирования, что позволяет учитывать и качественные факторы

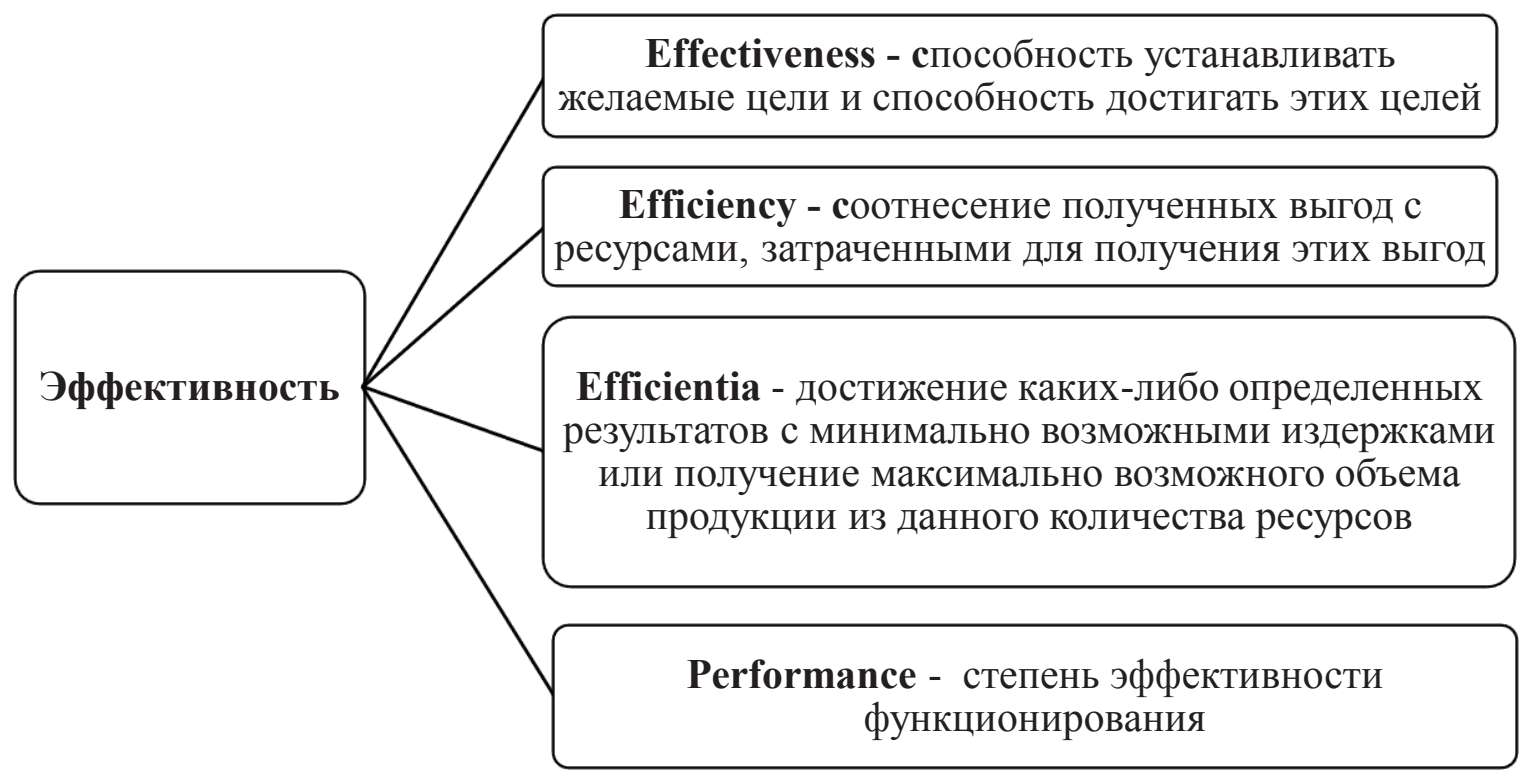

Рис. 1. Соотношение переводов отдельных терминов, трактующих понятие «эффективность» 
и параметры. Термин «Efficientia» иногда заменяется «productivity» - продуктивность, производительность.

В теории эффективности принято выделять задачи анализа и синтеза при проведении структуризации целей функционирования системы (рис. 2) [24].

В теории эффективности, как правило, принято учитывать три типа показателей эффективности процесса:

- степень достижения цели (целеполагание).

- затраченные ресурсы (ресурсоемкость и производительность процесса).

- затраты времени (оперативность процесca).

В совокупности указанные показатели порождают комплексное свойство - эффективность процесса или степень его приспособленности к достижению цели [23].

Как свойство системы эффективность характеризуется понятием интенсивности своего проявления. Меру интенсивности проявления эффективности называют показателем интенсивности W [10].

Более широкое определение: «показатель эффективности системы - это количественная характеристика конечного результата ее функционирования и развития в течение обуслов- ленного периода в сравнении с целевым нормативом и расходом ресурсов при заданных характеристиках состояния системы и воздействия внешней среды, а также при заданном векторе управления». В работе Ю.С. Соломонова показатель эффективности характеризуется как обобщенный показатель эффективности системы» [15], определяемый как:

$$
W=f\left(E_{v f}, E_{c} ; T_{v f} ; T_{\min }\right)
$$

где $E_{v f}-$ возможный или фактически достигнутый эффект (конечный результат) функционирования и развития системы; $E_{c}-$ целевой полезный эффект (необходимый конечный результат) функционирования развития системы; $T_{v f}$ - возможные или фактические затраты количества труда (живого и прошлого) для получения достигнутого полезного эффекта; $T_{\min }-$ минимальные необходимые затраты количества труда (живого и прошлого) для получения целевого полезного эффекта.

Из приведенного выражения следует, что можно рассматривать эффективность как возможную величину, фактически полученную, определяя тем самым степень достижения цели за определенный период функционирования системы.

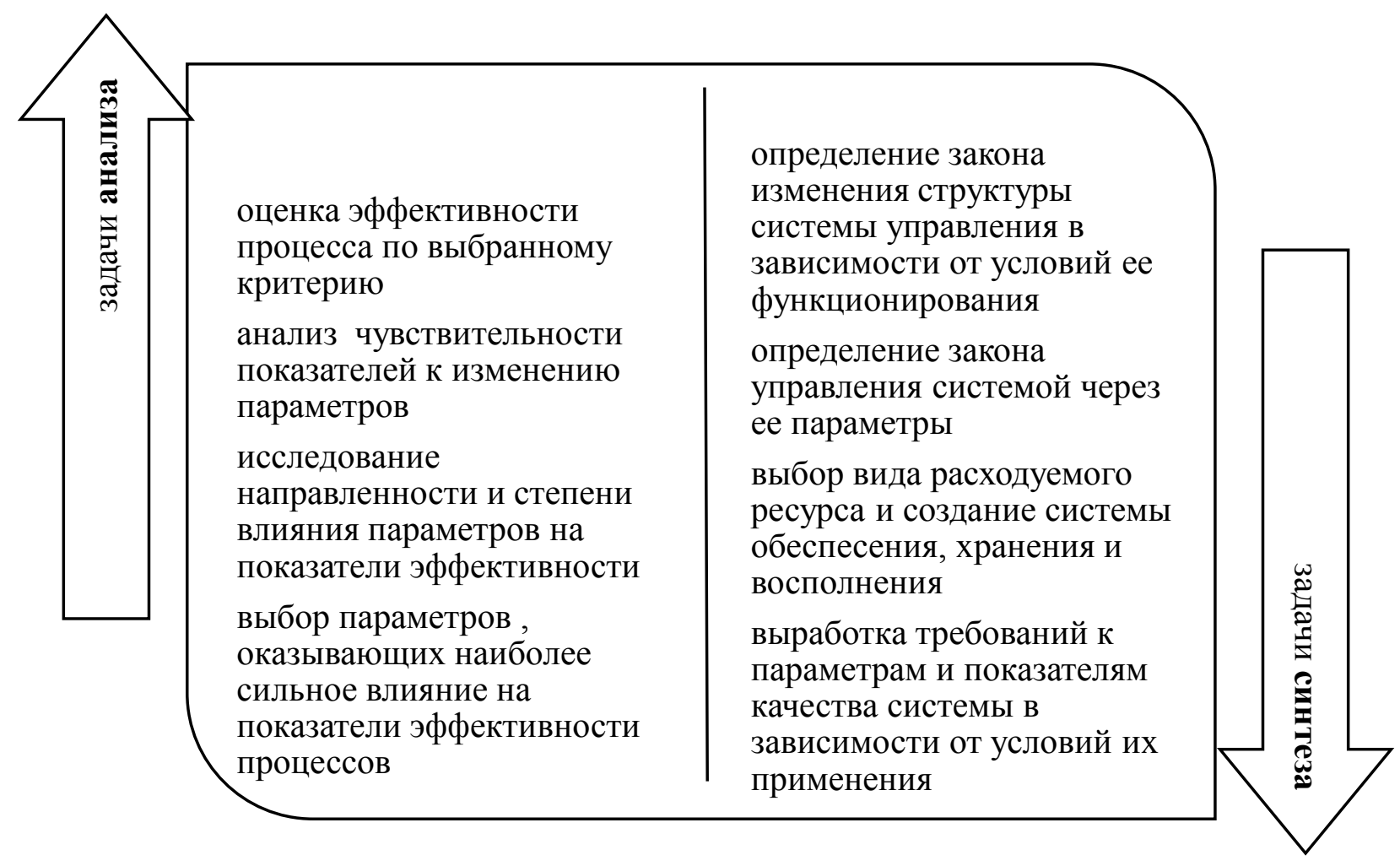

Puc. 2. Соотношение задач анализа и синтеза эффективности в теории эффективности 
Подходы к определению и оценке экономической эффективности

Исходя из современных воззрений понятие экономической эффективности принято рассматривать с трех позиций:

- как степень достижения организацией (социально-экономической системой) своих целей - управление/организация;

- как эффективность капиталовложений и/или внедрения новых проектов (инноваций, системных нововведений) как измерение абсолютного эффекта при инвестиционных мероприятиях (например, чистой текущей стоимости (NPV)) и измерение относительного эффекта (например, внутренняя норма рентабельности (IRR). Заметим, что в условиях плановой экономики широко использовался подход сравнительной эффективности двух систем (например, сравнение гибкой производственной системы и ряда отдельных станков, выстроенных в производственную линию), однако, в ряде работ доказывается некорректность такого подхода в силу различности сравниваемых систем [6];

- как рациональное использование имеющихся ресурсов (эффективность операционной деятельности).

Сформулировать конечную цель управления эффективностью можно как максимизацию соотношения результатов к тем ресурсам, которые были затрачены на их получения, а в соответствии с принципами маржинализма - максимизация результата на единицу затрат. В работах В.В. Новожилова подчёркивается, что понятия эффективности и оптимальности тождественны друг другу, при этом оптимизационные задачи звучали как «Минимизация затрат при достижении заданных результатов и максимизации результатов при заданных затратах (это двойственные минимаксные задачи)» [11].

Для расчета минимума приведенных затрат использовался так называемый нормативный коэффициент эффективности капиталовложений. Приведенные затраты позволяют оценить показатель сравнительной экономической эффективности того или иного данного решения минимум которого является критерием выбора варианта из рассматриваемых альтернатив.

Приведенные затраты определяются по формуле:

$3 \Pi=C+E K$, где $C$ - себестоимость производства товара, $K$ - капитальные вложения (инвестиции), необходимые для производства, $E-$ нормативный коэффициент эффективности капитальных вложений (равный обратной величине срока окупаемости). Устанавливались (централизованно) нормативные коэффициенты эффективности капитальных вложений $(0,12)$ и эффективности новой техники $(0,15)[18]$.

Известная проблема измерения эффективности связана с ограничениями параметров концепции дисконтированных денежных потоков. Определить величину будущих денежных потоков достаточно трудоемко и рискованно, особенно в условия риска и изменения внешней среды. Этот широко применяемый подход был предложен М. Мертоном и Ф. Модильяни [9], заложившими основы стоимостного подхода к анализу эффективности (VBM).

Можно отметить и следующее утверждение об эффективности в рамках стоимостной концепции «...под эффективностью в рамках принятой стоимостной концепции понимается максимизация РСП (рыночная стоимость предприятия) при условии соответствия достигнутых результатов деятельности предприятия поставленным целям. При этом критерием эффективности является достижение требуемых результатов инвестиций (инноваций) при приемлемой доходности (отдачи на капитал) за вычетом затрат на привлечение инвестиционных ресурсов которые являются финансовыми издержками, не создающими стоимости» [20]. Таким образом, уточняется абсолютное значение эффективности с точки зрения стоимостной концепции.

Если эффективность - это степень достижения организацией своих целей при использовании ограниченных ресурсов, то основными показателями эффективности являются качественные или количественные показатели, способные формализовать планируемые цели развития организации и измерить степень их достижения. Под эффективностью, по ГОСТ Р ИСО 9000:2001, понимается «связь между достигнутым результатом и использованными ресурсами» [3].

Итак, в современной экономической теории эффективность - это результативность или относительный эффект (деятельности организации, предприятия, корпорации, инвестиционного проекта, крупной сделки, инновации, финансового учреждения и др.), определяемый 
отношением полученным (ожидаемым) результатом (эффектом) к совокупным затратам капитального и операционного характера (расходам, издержкам, ресурсам), необходимым для достижения поставленной цели развития с учетом воздействия факторов внешней и внутренней среды.

Целевая установка подобных соотношений, согласно экономической теории и теории систем - стремиться к максимуму, решая известную экономическую задачу наиболее эффективного распределения ресурсов в условиях их ограниченности. А с точки зрения маржинальной теории часто устанавливается задача максимизации эффекта (результата) на единицу затрат.

\section{Эволюция категории «эффективность» в экономической науке.}

Термин эффективность «перешел» в экономику из технических наук. Однако первые упоминание о ней есть и у древних философов относительно вопросов обеспечения эффективности хозяйства (земельных угодий, в сельском хозяйстве) и рационального сочетания факторов производства [5]. Аристотель в работах «Никомахова этика» и «Политика» раскрывает экономические проблемы «справедливой цены товара», которая должна отражать затраты труда на его производство. При этом, он разделял собственно «экономику» - натуральное хозяйства и «хрематику», включавшую крупную торговлю и ростовщичество и отрицательно характеризовавшуюся со стороны этики («деньги не рождают деньги» - это эксплуатация кредитором должника). Подобное же отношение к анализу роли денег и у других мыслителей - Ксенофонт «Домострой», Фома Аквинский «Сумма богословия» [13].

Представители классической экономической теории А. Смит, Д. Рикардо и другие категорию «эффективность» практически в экономике не использовали, поскольку А. Смит считал, что экономические законы - объективная реальность, а Д. Рикардо обозначил зависимость стоимости продуктов от труда, а также выявил основную задачу классической политической экономии - определение законов, управляющих распределением доходов. К. Менгер в 1870х годах выявил концепции общественного блага и субъективной ценности, где представил товар как носитель свойств, которые несут определен- ную ценность для потребителя. С помощью трудов маржиналистов была создана теория бизнес-процессов, цель которых - удовлетворение потребностей и запросов клиента. В экономической теории термин «эффективность» впервые появляется в трудах В. Парето. Его модель экономической эффективности показывает, что когда любое изменение распределения ресурсов ухудшает благосостояние одного элемента экономической системы, то благосостояние общества достигает максимума и распределение ресурсов становится оптимальным.

Модель Парето дополнил А.Пигу, обозначив индивидуальное благосостояние как совокупность экономического благосостояния и нематериальных факторов, таких как условия окружающей среды, условия жизни, характер выполняемой работы, социально положение, порядок и безопасность в обществе, взаимоотношения с ним.

Под эффективностью размещения ресурсов (аллокативной эффективностью) экономисты понимают эффективность по Парето: «Эффективным по Парето является такое состояние экономики, при котором нельзя улучшить положение хотя бы одного субъекта, не ухудшая положения других. Критерий эффективности Парето состоит из трех частей: эффективность в обмене, ...в производстве и ...в структуре выпуска продукции» [2]. Автор «Курса политической экономии» (1897), в котором развил идею общего равновесия. Парето раскрывает дилемму между стремлением анализировать общественное благосостояние и невозможностью сравнивать индивидуальные полезности, определяя максимум как состояние (при этом допускается некоторое межличностное сравнение): «благосостояние увеличивается, если некоторые люди выигрывают и никто не проигрывает, благосостояние уменьшается, если некоторые люди теряют, но никто не выигрывает». Критерий Парето - максимум благосостояния достигается, «когда ничье благосостояние не может быть улучшено без ухудшения благосостояния кого-либо. При этом несовершенствами рынка (market failures) называются ситуации, когда Парето-эффективное состояние недостижимо по объективным экономическим причинам - монопольная власть продавца или покупателя, внешние эффекты, общественные блага, асимметрия информации. Внешние эффекты - полезность или затраты, не учтенные в цене продукции. Если не учтена по- 
лезность, имеет место положительный внешний эффект, если затраты - отрицательный внешний эффект. Интернализация внешнего эффекта - отражение внешнего эффекта в цене продукции» [8].

Термин «парадокс (эффект) Джевонса» в экономике означает, что увеличивающий эффективность использования ресурса технологический прогресс способен увеличивать объем потребления этого ресурса, а не уменьшать. Уильям Стэнли Джевонс, английский экономист, в 1865 году подчеркнул, что увеличивающие эффективность использования угля технологические усовершенствования приводят к увеличению потребления этого ресурса в промышленности.

Этот же вопрос был раскрыт и изучавшими обратный эффект потребления от увеличения энергоэффективности современными экономистами. Было выявлено, что к уменьшению необходимого для определенного применения объема увеличение эффективности уменьшает относительную стоимость использования ресурса, что приводит к повышению спроса на данный ресурс и потенциально ограничивает экономию от повышенной эффективности. Помимо этого, увеличение производительности ускоряет экономический рост, при этом увеличивается спрос на данный ресурс.

«Истинная эффективность - писал Эмерсон - всегда дает максимальные результаты при минимальных усилиях. Но условием для того должна стать созидательная организация» [19].

Нужно отметить, что привлечение частного капитала в экономику трансформирует принципы и подходы к оценке эффективности деятельности предприятий. Одним из наиболее значимых в современных условиях направлений является подход максимизации РСП, связанный со «стоимостной концепцией» и основанный на принципах, приведенных на рис. 3. [20].

Критерии выбора и целеполагания, показатели эффективности

Основой выбора критерия эффективности является его согласованность с целями функционирования системы. Следовательно, подчеркнем, что понятия «цель» и «эффективность» тесно взаимосвязаны, могут быть измерены (техническими средствами, количественными методами) на основе так называемых нормативов, но описаны качественно (вербально, когнитивно), а Р. Акоффом [1] впервые было введено понятие «целеустремлённой» системы.

\section{Базовые принциы экономпческой науки применительно к проблеме управленшя РСП}

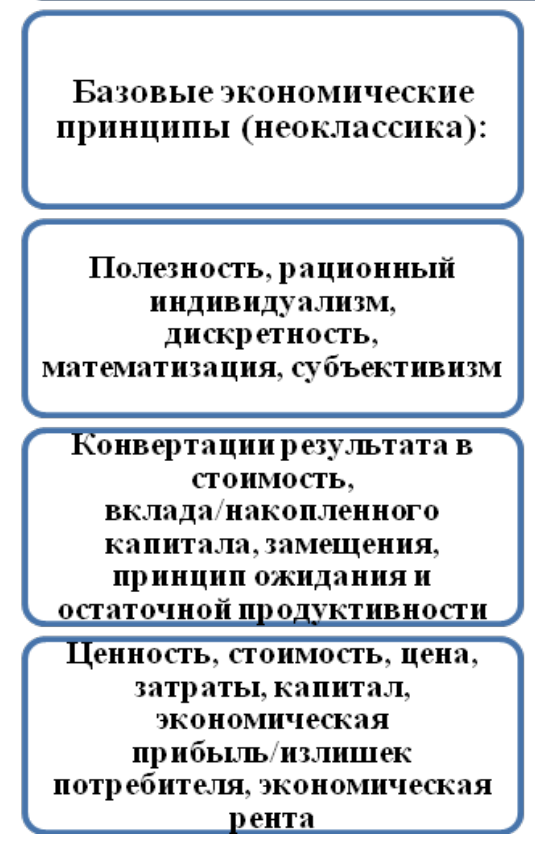

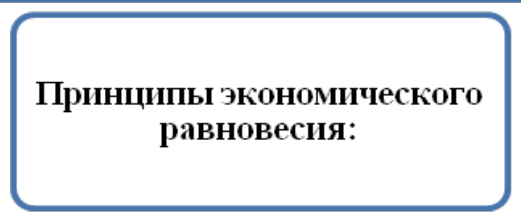

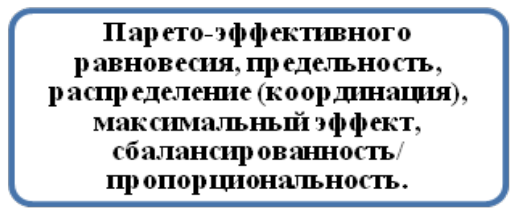

Предельность/маржинальность, эффекты благосостояния, Слаг аемости стоимостей, Принщш соотв етствия

Альтернативные издержки, жизненный цикл, экономпческая добавленная стоимость, цена капттала,
Принципы воздействия внешней среды и риска:

Зависимости от внешней среды, информаци, неопр еделенность, риск, адаптации, принци изменения стопмости, пр оцессность

Синергии, мотивация, адаптаци, конкуренци, регрессиш/пр огр ессиш, управленческая гибкость

Денежные потоки, риск, дисконтир ование/приведение, дезинв естици, финансовьй рьгтаг 
Для анализа и измерения экономических эффектов и эффективности (ЭЭ) на практике могут использоваться показатели - норматив чистой прибыли, экономическая прибыль с учетом финансовых издержек по всем источникам финансирования, рентабельность продаж, рентабельность инвестированного или /собственного капитала, прибыль на акцию.

Для измерения степени достижения стратегических целей могут быть использованы показатели чистой текущей стоимости (NPV), внутренней нормы доходности (IRR), дисконтированного срока окупаемости (DPBP) и т.д. индекса рентабельности инвестиций (табл. 1).

Итак, в качестве критериев выбора могут быть:

- управленческая и организационная значимость получаемых результатов;

- экономические результаты деятельности организации в стоимостной оценке;

- социально-общественная значимость и экологические результаты.

Эффективность деятельности предприятия оценивается посредством критериев оценки эффективности осуществляемых инвестиций (инвестиционной привлекательности), платежеспособности, кредитоспособности, ликвидности и оборачиваемости используемых в инвестиционном процессе активов, т.е. с точки зрения финансового подхода к управлению. Отсюда вытекает необходимость оценки именно рыночной, инвестиционной и стоимости для акционеров предприятия (РСП).

В настоящее время наиболее часто формирование эффективности рассматривается на основе процессного подхода, в соответствии с существующими в организации бизнес-процессов и цепочек создания стоимости. В систему показателей эффективности бизнес-процессов можно включить следующие:

- объем выпускаемой продукции соответствующего качества за определенный период

Таблица 1. Виды экономических систем и показатели оценки их эффективности

\begin{tabular}{|c|c|}
\hline Вид системы & Показатель эффективности функционирования данной системы \\
\hline Информационная & $\begin{array}{l}\text { Скорость обработки информации / Затраты на обеспечение данного параметра } \\
\text { системы }\end{array}$ \\
\hline Финансовая & $\begin{array}{l}\text { Прирост финансовых ресурсов (денежного капитала) / Абсолютная величина } \\
\text { финансовых ресурсов (денежного капитала) }\end{array}$ \\
\hline Инновационная & $\begin{array}{l}\text { Экономический эффект (другой результат) / Затраты капитального и текущего } \\
\text { характера, вызвавшие данный эффект (другой результат) }\end{array}$ \\
\hline Техническая & $\begin{array}{l}\text { Изменение производительности системы / Затраты, обеспечивающие прирост } \\
\text { производительности }\end{array}$ \\
\hline Инвестиционная & $\begin{array}{l}\text { 1. } 3 i=C i+E n \text { х Ki, где } 3 i-\text { приведенные затраты по проекту; } C i-\text { текущие } \\
\text { затраты; } K i-\text { величина капиталовложений; } E n-\text { нормативный коэффициент } \\
\text { эффективности капитальных вложений. } \\
\text { 2. В рамках теории временной стоимости денежных средств: } \\
\text { Свободный дисконтированный поток }(F C F) \text {, внутренняя норма доходности } \\
\text { (рентабельности) }(I R R, M I R R), \text { индекс доходности }(P I) \text {, дисконтированный срок } \\
\text { окупаемости }(P B P) \text {. Положительное значение } N P V>0 \text {, превышение порогового } \\
\text { значения IRR>CC является критерием отбора }\end{array}$ \\
\hline Производственная & $\begin{array}{l}\text { 1. Общие: } \\
- \text { производительность труда: } \\
P=Q / N \text { или } P=Q / T, \text { где } \\
Q-\text { объем произведенной продукции в стоимостном или натуральном выра- } \\
\text { жении; } N-\text { численность занятых на предприятии (организации); } T \text { - затраты } \\
\text { труда в стоимостном выражении; } \\
\text { - затраты на один рубль реализованной продукции; } \\
\text { - прибыль (результат) на один рубль затрат на производство и реализацию } \\
\text { продукции; } \\
\text { - экономическая добавленная стоимость }(E V A): E V A=I C \text { * (ROIC - WACC), где } \\
\text { IC- инвестированный капитал, ROIC - рентабельность инвестированного } \\
\text { капитала, WACC - средневзвешенная стоимость капитала. } \\
\text { 2. Показатели эффективности использования труда (темп роста производи- } \\
\text { тельности, трудоемкость, использование полезного фонда рабочего времени, } \\
\text { зарплатоемкость продукции). } \\
\text { 3. Показатели эффективности использования производственных фондов (фон- } \\
\text { доотдача, фондоемкость, рентабельность ОПФ, материалоемкость, капиталоем- } \\
\text { кость, капиталоотдача... и т.п.). }\end{array}$ \\
\hline
\end{tabular}


времени;

- количество потребителей продукции/работ/услуг;

- последовательное множество типовых производственных операций с заданной ритмичностью производства и операционного цикла;

- расходы на производство продукции (на единицу продукции или весь объем производства);

- длительность операционного (производственного) цикла;

- объем инвестиций в производство.

Современный подход к производству и производственной системе предприятия значительно шире: это не просто способ организации производства на уровне цеха, охватывающий полностью стадии производственной (операционной), сбытовой деятельности, но и такое «интегрированное производственное предприятие», на котором все его подразделения участвуют в процессе принятия управленческих решений (например, в сетевой модели управления) и выработке (корректировке) стратегии развития. Как и в любой системе, обязательно наличие обратной связи в виде функции планирования, контроля, корректировки планов и стратегии развития. Эффективность производственных систем заключается в управлении материально-техническими запасами, рабочими операциями, обслуживании оборудования, управлении материальными потоками, управлении качеством, трудовыми ресурсами (табл. 1). В рамках производственного процесса следует отдельно измерять эффективность использования оборотного капитала. Это возможно проанализировать на основе оценки оборачиваемости чистого оборотного капитала (в долях или днях); загрузки оборотных средств; величина высвобождаемых оборотных средств, рентабельности оборотного капитала. Можно также определить эффект, полученный от инвестирования средств в дебиторскую задолженность, на основе расчета дополнительной прибыли предприятия вследствие применения схемы товарного кредитования показателя с учетом затрат по его оформлению обслуживанию денежной наличности и потерь при невозврате задолженности.

В завершении необходимо отметить большое разнообразие подходов к измерению эффективности. Пример тому служат экономические методы оценки инвестиционных проектов (со всеми ограничения конкурентного совершенного рынка, противоречиями и ограничениями) $[4,14,25]$.

В настоящее время можно констатировать, что попытка реализации постулатов рыночной экономики в хозяйственный механизм Российской Федерации явно не была успешной, об этом свидетельствуют материалы заседаний Государственной Думы (например, материалы в «Парламентской газете от 17 марта 2017 г., итоги экономического форума 2016 г. в Петербурге, отчеты Столыпинского клуба, отчеты Института народнохозяйственного прогнозирования РАН), т.е. в современных условиях социально-экономическая эффективность и конкурентоспособность деятельности компании и ее будущее развитие основывается, в первую очередь, на измерении эффективности с позиции стоимостного похода в системе стратегического планирования и управления в целом. Во-вторых, измерение стоимости само по себе, тоже не может быть всеобъемлющим индикатором социальной эффективности их значимости, а значит, требуется комплексный подход к измерению эффективности деятельности.

Эффективность деятельности предприятия служит для инвесторов гарантом инвестиционной и финансовой привлекательности. Поэтому особое значение и актуальность имеет оценка результатов деятельности компании и в настоящем и планируемом будущем и стратегия (план) как ряд мероприятий по достижению социально-значимых целей, а значить необходимо завершать стоимостной анализ формированием плановых задач.

\section{Библиографический список}

1. Акофф, Р.Л. О целеустремленных системах [Текст] / Р.Л. Акофф, Ф. Эмери. Москва. 1974. 272 с.

2. Блауг М. Парето, Вильфредо // 100 великих экономистов до Кейнса Great Economists before Keynes: An introduction to the lives \& works of one hundred great economists of the past. Санкт-Петербург. 2008. С.233235.

3. ГОСТ Р ИСО 9000-2001 Государственный стандарт Российской Федерации, http://www.unilib.neva.ru/dl/ quality/std/gsriso90002001.html 
4. Дамодаран А. Инвестиционная оценка. Инструменты и техника оценки любых активов: пер. с англ. Москва. Альпина Бизнес Букс, 2004. 1324 с.

5. Катон старший (234-149 гг.), Варром (115-27 гг. до н.э.), Сенека (4-65 гг.н.э.) Лукреций Кар (39-55 гг.), Колумелла (1 в.н.э.) / Блауг М. Экономическая мысль в ретроспективе: пер. с англ. 4-е изд. Москва. Дело, 1994. -720 с.

6. Козловская Э.А. Организационно-экономические методы управления повышением эффективности производства при внедрении системных нововведений НТП: дисс. на соиск.д.э.н., Ленинград, 1991. 500 с.

7. Колмогоров А.Н. Автоматы и жизнь // Кибернетика ожидаемая и кибернетика неожиданная. Москва. 1968. C. 10-29.

8. Коуз. Р.Г. Природа фирмы. Вехи экономической мысли / под редакцией В.М. Гальперина/ Том 2. Теория фирмы. Санкт-Петербург. 2000.- 534 с.

9. Модильяни Ф., Миллер М. Сколько стоит фирма? Теорема ММ: Пер. с англ. 2-е изд. Москва. 2001. 272 с.

10. Надежность и эффективность в технике [Текст]: справочник / Ред. совет: В.С. Авдуевский (пред.) и др. В 10 т. Т.1. Методология. Организация. Терминология / Под ред. А.И. Рембезы.- М.: Машиностроение, 1986. - 224 c.

11. Новожилов В.В. Проблемы измерения затрат и результатов при оптимальном планировании. Москва. 1967. 207 c.

12. Петухов Г.Б. Методологические основы внешнего проектирования целенаправленных процессов и целеустремленных систем [Текст] / Г.Б. Петухов, В.И. Якунин. Москва. 2006. 504 с.

13. Розмаинский И.В., Холодилин К.А. История экономического анализа. Текст лекций. Москва. 2013.213 с.

14. Смоляк С.А. Оценка эффективности инвестиционных проектов в условиях риска и неопределенности (теория ожидаемого эффекта). Москва. 2002. 182 с.

15. Соломонов Ю.С. Большие системы: гарантийный надзор и эффективность [Текст] / Ю.С. Соломонов, Ф.К. Шахтарин. Москва. 2003. 368 с.

16. Флейшман Б. С. Элементы теории потенциальной эффективности сложных систем [Текст] / Б.С. Флейшман. Москва.1971.224 с.

17. Флейшман Б.С. Теория потенциальной эффективности. Интервью с Г. Гореликом. URL: http://ggorelik.narod. $\mathrm{ru} /$ ZS_etc/Vybor.htm

18. Хачатуров Т.С. Эффективность капитальных вложений. Москва. 1979; Методика (основные положения) определения экономической эффективности использования в народном хозяйстве новой техники, изобретений и рационализаторских предложений. Москва, 1977.

19. Эмерсон Г. Двенадцать принципов производительности (науч. ред. В.С. Кардаш). 2-е изд. Москва. 1992.216 c.

20. Яковлева Е.А. Управление стоимостью промышленного предприятия в условиях инновационного развития. Диссертация на соискание ученой степени доктора экономических наук / Санкт-Петербургский университет экономики и финансов. Санкт-Петербург, 2009.

21. URL: Coelli, T. An Introduction to Efficiency and Productivity Analysis [Text] / T. Coelli, D.S. Prasada Rao, G.E. Battese.- Boston: Kluwer Academic Publishers, 1998. - 275 p.

22. Cooper W. W. Data Envelopment Analysis [Text]: A Comprehensive Text with Models, Applications, References, and DEA-Solver Software / W.W. Cooper, L. M. Seiford, K. Tone.-Boston: Kluwer Academic Publishers, 2000. - 318 p.

23. URL: http://victor-safronov.ru/systems analysis/lectures/rodionov/09.html

24. URL: http://www.strategplann.ru/ui/teorija-effektivnosti.html

25. URL: http://www.cfin.ru/management/controlling/performance_evaluation. shtm 